\title{
SCIDoc

\section{Central Venous Oxygen Saturation Behavior In Patients Under General Anesthesia}

Research Article

Madrid Díaz G ${ }^{1}$, Niño de Mejía MC ${ }^{1}$, Amaya Bernal O ${ }^{1}$, Ferrer Zaccaro L ${ }^{1}$, Hernández Santamaría JE², González La Rotta M¹, Sergio D Bergese $3^{*}$

${ }^{1}$ Fundación Santa Fe de Bogotá, Colombia.

${ }^{2}$ Universidad El Bosque, Colombia.

${ }^{3}$ The Ohio State University Wexner Medical Center, USA.

\section{Abstract}

Introduction: Venous oxygen saturation is a metabolic variable that complements the information provided by hemodynamic parameters and globally evaluates the oxygen delivery and consumption by bodily tissues. Its precise values under general anesthesia are unknown, and constitutes an area of great interest for research.

Objectives: To evaluate the effect of general anesthesia on Central Venous Oxygen Saturation $\left(\mathrm{SvcO}_{2}\right)$ in patients undergoing major surgical procedures.

Methods: Aquasi-experimental before-after study in which central venous oxygen saturation $\left(\mathrm{SvcO}_{2}\right)$ values were obtained by gasometry and compared before the induction of anesthesia and 30 minutes after initiation of ventilatory support. The study included 111 patients undergoing major surgery under general anesthesia, grouped into 3 age groups.

Results: There is a statistically significant increase in $\mathrm{SvcO}_{2}$ from baseline values of $66.29 \%$ to $76.89 \%(15.99 \%, \mathrm{p}<0.05)$ in patients under general anesthesia.

Conclusion: $\mathrm{SvcO}_{2}$ increases significantly in patients of all ages under general anesthesia. The aforementioned results are important when re-evaluating the pre-established reference values in the various clinical settings requiring general anesthesia.

Keywords: Oxygen Venous Saturation; Oxygen Delivery; Oxygen Consumption; General Anesthesia; Central Venous Oxygen Saturation.

\section{Introduction}

Anesthetic care underwent significant changes over time due to scientific growth and development of new techniques for perioperative monitoring.

Central venous oxygen saturation $\left(\mathrm{SvcO}_{2}\right)$ is a variable of great interest, since it complements hemodynamic information by evaluating oxygen supply, consumption, and global use [1-4].

General anesthesia diminishes the body's metabolic rate and oxygen requirements, therefore an increase in $\mathrm{SvcO}_{2}$ is expected [57]. This phenomenon has not yet been reported in the medical literature, and precise values of $\mathrm{SvcO}_{2}$ under general anesthesia remain unknown. Furthermore, contradictory reports describe
$\mathrm{SvcO}_{2}$ changes in different clinical settings $[2,3,6,7]$.

Because of the existing controversies, it is essential to analyze $\mathrm{SvcO}_{2}$ in patients undergoing surgery with general anesthesia to establish the normal reference values for this parameter. Such values can be suggested for specific clinical situations, optimizing perioperative clinical care.

\section{Methods}

\section{Patient Selection}

We included patients without randomization aged 18 years or older undergoing major elective surgeries under general anesthesia and requiring the placement of a central line for routine monitor-

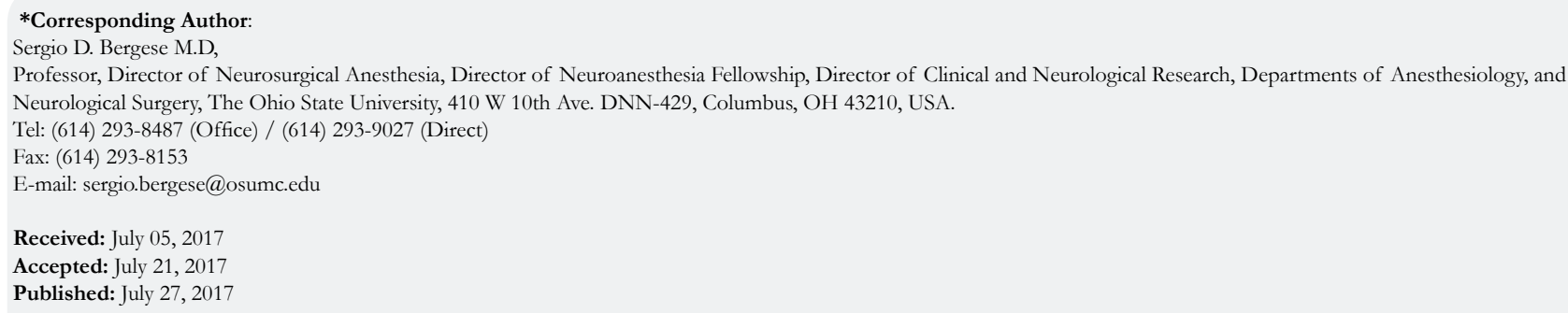

Citation: Madrid Díaz G, Niño de Mejía MC, Amaya Bernal O, Ferrer Zaccaro L, Sergio D Bergese, et al., (2017) Central Venous Oxygen Saturation Behavior In Patients Under General Anesthesia. Int J Anesth Res. 5(6), 452-455. doi: http://dx.doi.org/10.19070/2332-2780-1700093

Copyright: Sergio D Bergese $^{\circ}$ 2017. This is an open-access article distributed under the terms of the Creative Commons Attribution License, which permits unrestricted use, distribution and reproduction in any medium, provided the original author and source are credited. 
ing. We excluded patients with cardiac disease and low ejection fraction, patients with chronic lung disease requiring supplementary oxygen therapy, pregnant women, patients with systemic inflammatory response syndrome by any cause, and those who were hemodynamically unstable at the time of second blood sample collection. All patients signed written informed consent before initiating study-related procedures. The study was conducted during a period of 6 months from August to December 2010 at Fundación Santa Fe de Bogotá University Hospital.

The sample size of 111 patients was calculated to reach a power of $80 \%$ for the study. The alpha error was set at $<0.05(5 \%)$ for the mean differences in the $\mathrm{SvcO}_{2}$ values before induction of anesthesia and at 30 minutes after induction. The calculated sample size accounted for a 10\% drop-out rate.

\section{Data Collection}

The subjects were monitored with pulse oximetry, EKG, temperature, and non-invasive blood pressure; midazolam $3 \mathrm{mg}$ IV and propofol 30-50 mg IV were used to sedate the patients. A central line was placed, the first blood sample was obtained before anesthesia induction and the second blood sample was obtained at the initiation of mechanical ventilation, 30 minutes after induction $\left(\mathrm{FiO}_{2}=0.6\right)$. Both samples were analyzed with the I-STATC device. We recorded patient demographic information, type of surgery, $\mathrm{SvcO}_{2}$ from both blood samples, and vital signs during the surgical procedure. Data was exported and stored in a Microsoft Excel(C) database for further analysis. The following anesthesia regimen was used per standard operating procedures: propofol $1 \mathrm{mg} / \mathrm{kg}$, rocuronium $0.6 \mathrm{mg} / \mathrm{kg}$, remifentanil $0.1-0.15 \mathrm{mg} / \mathrm{kg} /$ min or fentanyl $1-5 \mathrm{mcg} / \mathrm{kg} / \mathrm{h}$, sevoflurane $0.5 \mathrm{MAC}$, and BIS between 40-60 (during maintenance).

\section{Statistical Analysis}

STATA 10@ software was used for data analysis, considering the variable measurement scale. Nominal and ordinal variables were described with absolute and relative frequencies. Continuous variables were described using means and standard deviations. To evaluate differences in the means, the Student's t-test for independent samples was applied, as well as a descriptive statistic of the involved variables. The surgical procedure characteristics were identified using central tendency and dispersion measures. For continuous variables: means, standard deviations, minimum and maximum values were used; for discrete variables: absolute frequencies and percentages were used. Frequencies and percentages were also used for nominal variables. $\mathrm{SvcO}_{2}$ was stratified by age group.

\section{Ethical Considerations}

This study did not compromise patient safety or quality of care. The protocol was designed based on Declaration of Helsinki international ethics recommendations and Colombian normativity regarding research involving human subjects (Resolution 8430 of 1993 by the Social Protection Ministry). Approval by the Institutional Ethics in Research Committee was obtained before execution of the study. Subject participation required a written informed consent.

\section{Results}

\section{General Considerations}

A total of 111 patients undergoing different types of surgeries were included in the study: cardiovascular surgeries (44), neurosurgical procedures (17), major abdominal surgeries (17), orthopedic surgeries (18), and other surgeries- head and neck, thoracic, and urologic procedures (15).

There was an equal gender distribution in the patient sample - male $(50.45 \%)$ and female $(49.55 \%)$. The age distribution included the following three categories - younger than 40 years old $(12.62 \%)$, between 41 and 60 years old $(50.45 \%)$, and older than 61 years old $(36.92 \%)$.

\section{Type of Procedure}

Cardiovascular surgical cases were the most frequently observed (39.6\%), followed by orthopedic procedures, neurosurgeries, and abdominal surgeries. The least frequently observed procedures were head and neck, thoracic, and urologic surgeries (Figure 1).

\section{Measurement of Variables}

The primary outcome measurement was $\mathrm{SvcO}_{2}$ variation before and after anesthesia induction. Mean heart rate, mean systolic/ diastolic blood pressure, arterial oxygen saturation, and body temperature constitute the secondary outcome variables.

There was a statistically significant increase in $\mathrm{SvcO}_{2}$ (Figure 2),

Figure 1. Type of Procedure Performed (Expressed as Percentage \%).

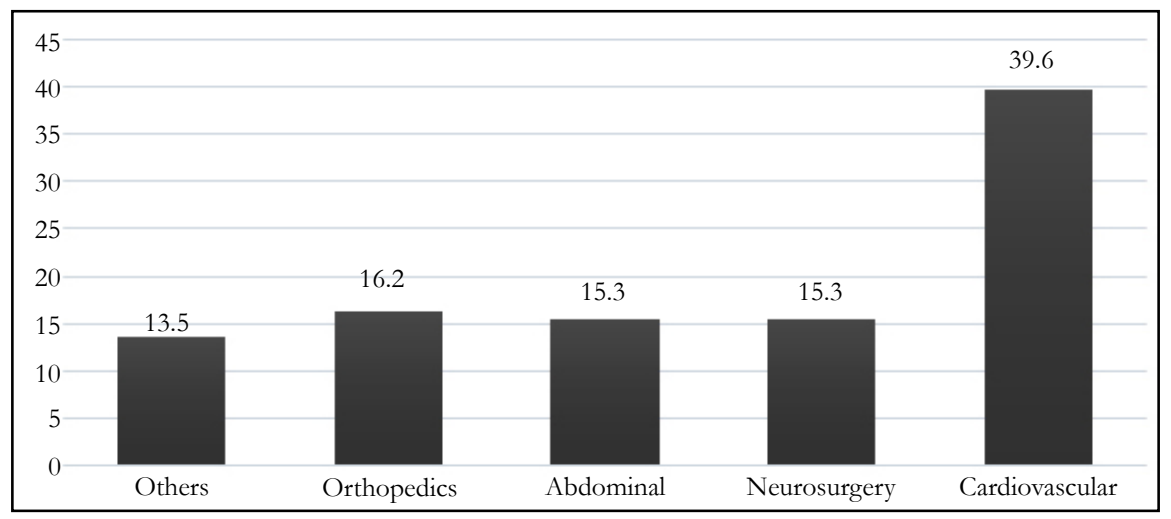


Figure $2 . \mathrm{SvcO}_{2}$ variation 30 minutes after induction of anesthesia.

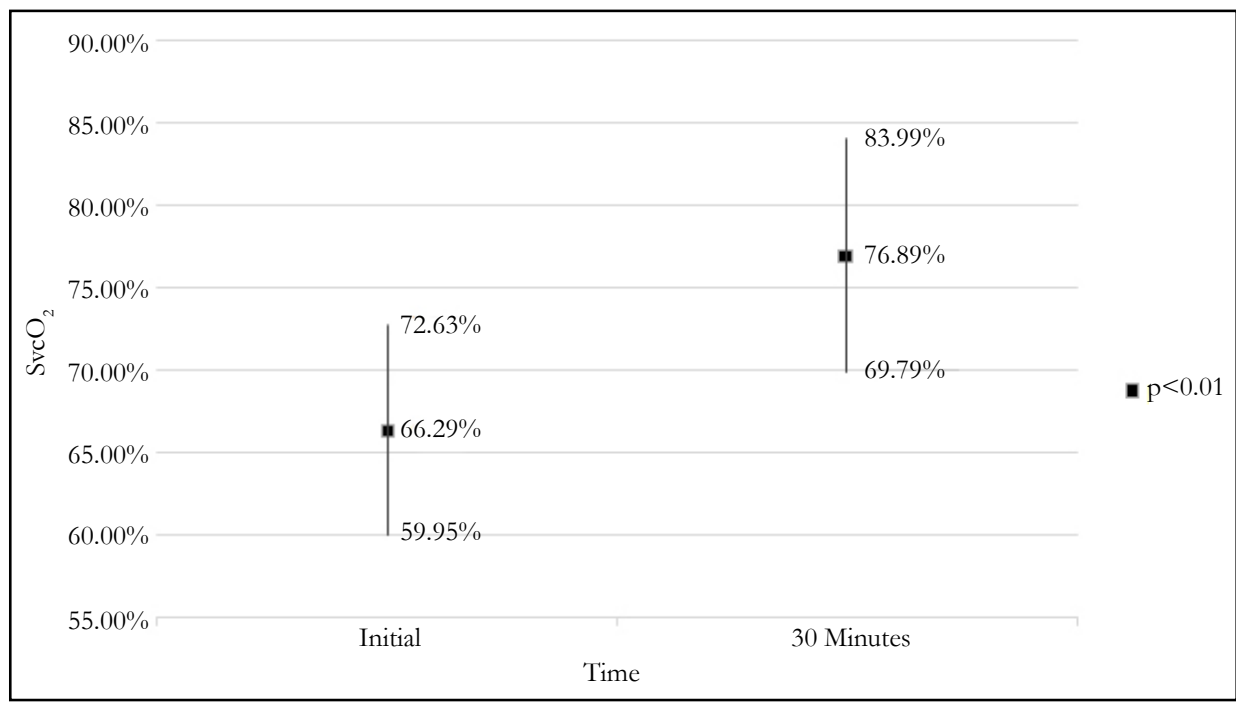

and a statistically significant decrease in mean heart rate $(70.52$ bpm to $67.33 \mathrm{bpm}, \mathrm{p}<0.05)$. The average systolic blood pressure decreased from $125 \mathrm{mmHg}$ to $106 \mathrm{mmHg}$ and diastolic blood pressure decreased from $73 \mathrm{mmHg}$ to $64 \mathrm{mmHg}$; however, these changes were not statistically significant, and were most likely explained by the drugs used during anesthesia induction and maintenance. Arterial oxygen saturation had a statistically significant increase $(94 \%$ to $98 \%, \mathrm{p}<0.05)$, owing to a rise in the fraction of inspired oxygen. Body temperature remained within a normal range, with a slight tendency toward decrease.

\section{Discussion}

The physiologic bases for the dynamic variation of $\mathrm{SvcO}_{2}$ are oxygen supply, cardiac output, arterial oxygen content, and tissue oxygen consumption $[2,8,9]$.

$\mathrm{SvcO}_{2}$ monitoring is an established means to optimize the clinical management of patients with sepsis, hypovolemia, anemia, and other critical conditions. In these conditions, values of $70 \%$ or higher are associated with improved mortality outcomes on the $28^{\text {th }}$ postoperative day $[8,9]$.

In our study, we proposed new $\mathrm{SvcO}_{2}$ reference values applicable to various clinical settings requiring general anesthesia. In patients under general anesthesia, an increase in $\mathrm{SvcO}_{2}$ is expected due to increased oxygen supply and reduced tissue oxygen consumption [5-9]. The main motivation for this study was the lack of a standardized $\mathrm{SvcO}_{2}$ value. We aimed to analyze the effect of general anesthesia on $\mathrm{SvcO}_{2}$ levels.

Our results show a statistically significant increase in $\mathrm{SvcO}_{2}$ after anesthesia induction, a $15.99 \%$ increase from its baseline value, suggesting that normal $\mathrm{SvcO}_{2}$ levels are higher than expected in this clinical setting. Taking these results into account, we could consider adjusting therapeutic goals in patients under general anesthesia, rather than relying solely on the pre-established values. There was no difference in $\mathrm{SvcO}_{2}$ values between the three age groups.

Secondary outcome variable analysis showed that heart rate, blood pressure and body temperature decreased, while arterial oxygen saturation was augmented. These results were expected, and were attributed to increased fraction of inspired oxygen $\left(\mathrm{FiO}_{2}=0.6\right)$ and administration of anesthetics. Nonetheless, these findings have no clinical impact or consequences on patient outcomes.

Central venous oxygen saturation $\left(\mathrm{SvO}_{2}\right)$ is one of the best indicators for tissue oxygen delivery $\left(\mathrm{DO}_{2}\right)$ and perfusion. $\mathrm{SvO}_{2}$ monitoring $\left(\mathrm{DO}_{2}-\mathrm{VO}_{2}\right)$ shows the balance between oxygen delivery $\left(\mathrm{DO}_{2}\right)$ and oxygen consumption $\left(\mathrm{VO}_{2}\right) \cdot \mathrm{DO}_{2}\left(\mathrm{CO} \times \mathrm{CaO}_{2}\right)$ is proportional to cardiac output $(\mathrm{CO})$ and arterial oxygen content $\left(\mathrm{CaO}_{2}\right)[10,11]$. Thus, in patients under general anesthesia with an adequate cardiac output, $\mathrm{SvO}_{2}$ depends mainly on $\mathrm{CaO}_{2}$. Likewise, $\mathrm{CaO}_{2}$ relies on the oxygen bound to hemoglobin (90\%) and the oxygen dissolved in blood (10\%). Because only a small fraction of oxygen is dissolved in blood, its impact on $\mathrm{CaO}_{2}$ is minimal $[10,11]$.

The fraction of inspired oxygen $\left(\mathrm{FiO}_{2}\right)$ modifies the dissolved oxygen $(10 \%)$, not the oxygen bound to hemoglobin. For this reason, $\mathrm{FiO}_{2}$ variation in patients under general anesthesia is not clinically significant. Cardiac output and hemoglobin levels were the variables that affected oxygen delivery the most; therefore, we excluded patients with low cardiac output, anemia, and any other condition that may alter these variables from our study $[10,11]$.

\section{Limitations}

Because this was a quasi-experimental before-after study, patients were not randomized into groups, and a heterogeneous population was included. Additionally, we did not analyze data considering differences in surgical procedures (type of surgery, length of surgery).

\section{Financial Disclosure}

This study was funded entirely by the Anesthesia Department at Fundación Santa Fe de Bogotá University Hospital. No external funding was received.

\section{Conclusion}

General anesthesia has a significant impact on $\mathrm{SvcO}_{2}$ values, with 
patients experiencing a $15.99 \%$ increase in $\mathrm{SvcO}_{2}$ from baseline values after anesthesia induction. These results allow us to introduce new therapeutic goals in this context, instead of focusing on normal ranges established for other clinical scenarios. Heart rate and arterial oxygen saturation underwent statically significant changes; however, these changes can be attributed to the anesthesia, and represent no clinical impact on patient outcomes.

\section{References}

[1]. Shepherd SJ, Pearse RM (2009) Role of central and mixed venous oxygen saturation measurement in perioperative care. Anesthesiology. 111(3): 64956.

[2]. Blasco V, Leone M, Textoris J, Visintini P, Albanèse J, et al., (2008) Venous Oximetry: Physiology and therapeutic. Ann Fr Anesth Reanim. 27(1): 7482.

[3]. Yazigi A, Abou-Zeid H, Madi-Jebara S, Haddad F, Hayek G, et al., (2008) Correlation between central venous oxygen saturation and oxygen delivery changes following fluid therapy. Acta Anaesthesiol Scand. 52(9): 1213-7.

[4]. Marx G, Reinhart K (2006) Venous oximetry. Curr Opin Crit Care. 12(3): 263-8.

[5]. Ho KM, Harding R, Chamberlain J (2008) The impact of arterial oxygen tension on venous oxygen saturation in circulatory failure. Shock. 29(1): 3-6.

[6]. Bauer P, Reinhart K, Bauer M (2008) Significance of venous oximetry in the critically ill. Med Intensiva. 32(3): 134-42.

[7]. Jee R, White N (2007) The effect of inspired oxygen concentration on central venous oxygen saturation. JICS. 8(3): 7-10.

[8]. Squara P (2014) Central venous oxygenation: when physiology explains apparent discrepancies. Critical Care. 18(6): 579.

[9]. Tánczos K, Molnár Z (2013) The oxygen supply-demand balance: a monitoring challenge. Best Pract Res Clin Anaesthesiol. 27(2): 201-7.

[10]. Reinhart K, Bloos F (2005) The value of venous oximetry. Curr Opin Crit Care. 11(3): 259-263.

[11]. Reinhart K, Kuhn HJ, Hartog C, Bredle DL (2004) Continuous central venous and pulmonary artery oxygen saturation monitoring in the criti- cally ill. Intensive Care Med. 30(8): 1572-1578. 